\title{
Hydrolytic and Photoinduced Degradation of Tribenuron Methyl Studied by HPLC-DAD-MS/MS
}

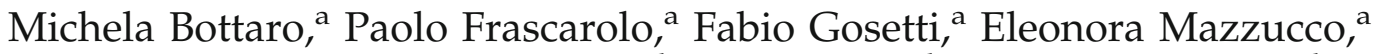 \\ Valentina Gianotti, ${ }^{\text {a }}$ Stefano Polati, ${ }^{\text {b }}$ Erika Pollici, ${ }^{\text {b }}$ Luciana Piacentini, \\ Giuseppina Pavese, ${ }^{\mathrm{b}}$ and Maria Carla Gennaro ${ }^{\mathrm{a}}$ \\ ${ }^{a}$ DISAV Dipartimento di Scienze dell'Ambiente e della Vita, University of Piemonte Orientale, Alessandria, \\ Italy \\ ${ }^{b}$ A.R.P.A. Piemonte, Laboratori del Quadrante Sud-Est, Alessandria, Italy
}

The@paper@studies,@with@the@help@of@HPLC-DAD-MS/MS@technique, $\mathbb{C}$ theChydrolytic@and photoinduced@degradation@processes@that@take@place@in@aqueous@solutions@of@tribenuron methyl,@oth@wen preserved@n@he@ark@nd@hen@indergoing@olar@ox@rradiation@inder

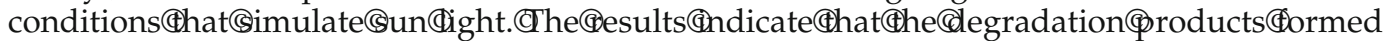
by@hydrolysis@alone@nd@y@hotoirradiation@re@he@ame,@but@inetics@f@he@hydrolysis reaction@is@much@slower.@The@degradation@products@are@identified@as@2-methoxy-4methylamino-6-methyl-1,3,5-triazine $₫ \mathrm{P} 1)$,@nethyl@2-aminosulfonylbenzoate $₫ \mathrm{P} 2), @$ and@accharin@P3)@nd@uantified.đcotoxicological@biotests@erformed@n@.1@ug L $\mathrm{L}^{-1}$ photoirradiated solutions of the herbicide give a border line toxicity situation comparable to that of the precursor and indicate that the herbicide is characterized by low persistence in the environment, as required. Its degradation, however, does not lead to mineralization but to the formation of products of comparable toxicity. To evaluate the matrix effects, the photodegradation of the herbicide is also studied in the presence of rice paddy waters: the process is slower than in ultrapure water but leads to the same products. Experiments performed for comparison by irradiating ultrapure water solutions with UV lamp $(254 \mathrm{~nm})$ show that the degradation process is not only faster with respect to sunlight, but gives a different pathway, without in anyway leading to mineralization. (J Am Soc Mass Spectrom 2008, 19, 1221-1229) (C) 2008 American Society for Mass Spectrometry

$\mathrm{T}$ The more recent herbicide formulations are designed to offer advantages of the highest selectivity together with the lowest persistence in the environment: sulfonylurea herbicides meet these requirements. But, unfortunately, lower persistence in the environment does not necessarily correspond to lower toxicity, since many herbicides undergo natural degradation reactions in the environment that do not lead to mineralization but to the formation of new species potentially more toxic and stable than the precursors [1-5]. The evaluation of the degradation pathway and the structures and toxicity of the degradation products is therefore of paramount importance.

The natural degradation of sulfonylurea herbicides takes place through aqueous hydrolysis reactions [6-8], microbial processes (mainly occurring in soils) [9-11], or photodegradation reactions $[1-3,5,12-14]$. These processes in surface waters and in soil are concomitant $[7,15,16]$.

Address reprint requests to Prof. M. C. Gennaro, University of Piemonte Orientale, DISAV Dipartimento di Scienze dell'Ambiente e della Vita, via Bellini 25/G, 15100 Alessandria, Italy. E-mail: gennaro@mfn.unipmn.it
HPLC-DAD-MS/MS methods are employed here to investigate and compare the hydrolytic and photoinduced degradation pathways of aqueous solutions of tribenuron methyl (methyl [2-4-methoxy-6-methyl-1,3,5-triazin-2yl(methyl)carbamoyl sulfamoyl]benzoate) (Scheme 1), largely used against broad-leaved weeds in crops of cereals and in particular of rice.

$\mathrm{TiO}_{2}$ assisted photodegradation often leads to complete mineralization and can be used to dissipate pollutants in remediation strategy [17-20]. We are interested here to study the natural photodegradation of tribenuron methyl in waters; the formation of degradation products and their identification are receiving increasing interest in laboratories involved in monitoring of surface waters and in particular of paddy waters. Degradation reactions induced by sun light are also of particular interest in the natural dissipation of pesticides in rice paddy waters [21], mainly when according to EC Directives [22] the absorptivity value $\varepsilon$ of the herbicide at wavelengths greater than $290 \mathrm{~nm}$ is greater than $10 \mathrm{~L} \mathrm{~cm}^{-1} \mathrm{~mol}^{-1} ; \varepsilon_{290 \mathrm{~nm}}$ of tribenuron methyl is $590 \mathrm{~L} \mathrm{~cm}^{-1} \mathrm{~mol}^{-1}$. 
<smiles>COC(=O)c1ccccc1S(=O)(=O)NC(=O)N(C)c1nc(C)nc(OC)n1</smiles>

Scheme 1

Some literature studies concern the formation of degradation products formed from tribenuron methyl and other sulfonylurea herbicides for the action of sun light, UV irradiation, or hydrolysis reactions [6, 16]. To avoid the simultaneous contribution of hydrolysis reactions and to consider only the effects of photodegradation, standard solutions have been prepared in organic solvents as acetonitrile [6] and methanol [8]. The use of hydro-organic solvent is also attributable to the relatively low solubility in water of sulfonylurea herbicides [10, 23, 24]. Methanol, isopropanol, and cyclohexane have also been chosen to model the action of tribenuron methyl towards plant cuticle constituents [24], and methylene chloride extracts were prepared for the GC-MS identification of intermediates [25]. But organic solvents, even at low percentages, are reported to affect the degradation pathway and the composition of the final degradation products since they can participate in the formation of intermediates and metastable adducts $[10,24,26]$. So, for example, the presence of isopropanol decreases the degradation rate of azimsulfuron [21], ethanolysis reactions take place in the presence of ethanol $[7,27,28]$, and methylation reactions in the presence of methanol [24].

To evaluate and compare the degradation pathways of tribenuron methyl induced by hydrolysis reactions (natural $\mathrm{pH}=5.7$ ) and by photoirradiation, two model solutions ( $5.00 \mathrm{mg} \mathrm{L}^{-1}$ ) in ultrapure water without any addition of organic solvent comparatively underwent natural hydrolysis reactions (in the dark and at room temperature) and to solar box irradiation.

Aliquots of solution, collected at prefixed times, are directly injected in the HPLC-DAD-MS system without any pretreatment, and the degradation products identified and quantified. The study is also performed on waters collected in a rice field, and the results obtained under the different conditions are compared.

\section{Experimental}

\section{Materials and Methods}

Tribenuron methyl (methyl 2-[4-methoxy-6-methyl1,3,5-triazin-2-yl(methyl)carbamoyl sulfamoyl]benzoate was purchased from Dr. Ehrenstorfer GmbH (Augs- burg, Germany). Stock solutions were prepared at 10.00 $\mathrm{mg} \mathrm{L}^{-1}$ concentration in ultrapure water.

HPLC grade acetonitrile (99.8\%) and glacial acetic acid $(99.8 \%)$ were purchased from Merck (Darmstadt, Germany), ultrapure water was produced by a Millipore Milli-Q system (Milford, MA).

Potassium dichromate (ACS-ISO-for analysis) was purchased from Carlo Erba (Milan, Italy), ammonium iron (II) sulfate hexahydrate $98 \%$, sulfuric acid $96 \%$, and ferroin indicator $0.1 \% \mathrm{wt} / \mathrm{vol}$ solution in water, methyl 2-(aminosulfonyl)benzoate $98 \%$ and 2-methoxy-4methylamino-6-methyl-1,3,5-triazine $96 \%$ were purchased from Sigma-Aldrich (Schnelldorf, Germany). Saccharin $\geq 99 \%$ was purchased from Fluka (Buchs, Switzerland).

\section{Apparatus}

HPLC-DAD-MS/MS analyses were carried out by a Thermo Finnigan Mat Spectra System (Finnigan, San Jose, CA) equipped with a Degasser SCM1000, a gradient pump Spectra System P4000, an Autosampler Spectra System AS3000, interfaced by the module SN4000 to a diode array detector Spectra System UV6000LP (190$700 \mathrm{~nm}$ ) and to a mass spectrometer detector Finnigan LCQ Duo, equipped with electrospray ionization (ESI) and atmospheric pressure chemical ionization (APCI) ion sources and with ion trap analyzer. A CoFoMeGra Solar box 3000e (Milan, Italy) was used to simulate sun light irradiation. An OSRAM UV lamp emitting at wavelength of $254 \mathrm{~nm}$ (power $15 \mathrm{~W}$ ) was used in the degradation experiments. The electronic counter used for toxicological test is a Beckman Coulter Z-1 particle counter and Z-2 size analyzer (Beckman Coulter, Fullerton, CA).

\section{HPLC-DAD-MS/MS Conditions}

The chromatographic conditions already optimized for the separation of a mixture of sulfonylurea herbicides were fitted to the separation of tribenuron methyl [29]. The stationary phase was a Lichrospher column RP-18 endcapped ( $5 \mu \mathrm{m}, 250 \mathrm{~mm} \times 4 \mathrm{~mm}$ i.d.) with a $15 \mathrm{~mm} \times$ $4 \mathrm{~mm}$ Lichrospher RP-18 (5 $\mu \mathrm{m})$ guard precolumn (Merck, Darmstadt, Germany). The mobile phase is a mixture $55 / 45 \% \mathrm{vol} / \mathrm{vol}$ of acetonitrile and acidified water $(0.05 \% \mathrm{vol} / \mathrm{vol}$ for acetic acid), flowing at $0.5 \mathrm{~mL}$ $\mathrm{min}^{-1}$. The eluate flow coming from the HPLC system was split 1:1 before introduction in ESI source. Diode Array Detector operates in the wavelength range 190$700 \mathrm{~nm}$. The limit of detection (LOD) is $7.4 \mu \mathrm{g} \mathrm{L}^{-1}$ and the limit of quantitation (LOQ) $25.0 \mu \mathrm{g} \mathrm{L}^{-1}$.

The mass spectrometry analyses were performed both in positive ion (PI) and negative ion (NI) modes. High purity nitrogen gas was used as nebulizer and helium (>99.999\%) served as quenching agent. Full scan data acquisition ( 3 microscans, 50 ms inlet time) was made over the range $m / z 50-500$. Method conditions are reported in Table 1. 
Table 1. Mass spectrometry method conditions

\begin{tabular}{|c|c|c|c|c|}
\hline & \multicolumn{2}{|c|}{ ESI } & \multicolumn{2}{|c|}{$\mathrm{APCl}$} \\
\hline & $\mathrm{PI}$ & $\mathrm{NI}$ & $\mathrm{PI}$ & $\mathrm{NI}$ \\
\hline Source voltage & $4.50 \mathrm{kV}$ & $-4.50 \mathrm{kV}$ & - & - \\
\hline Source current & - & - & $5.0 \mathrm{~mA}$ & $5.0 \mathrm{~mA}$ \\
\hline Capillary voltage & $+3.0 \mathrm{~V}$ & $-34.0 \mathrm{~V}$ & $+7.0 \mathrm{~V}$ & $-10.0 \mathrm{~V}$ \\
\hline Heated capillary temperature & $270^{\circ} \mathrm{C}$ & $270^{\circ} \mathrm{C}$ & $200^{\circ} \mathrm{C}$ & $200^{\circ} \mathrm{C}$ \\
\hline Source heater temperature & - & - & $450^{\circ} \mathrm{C}$ & $450^{\circ} \mathrm{C}$ \\
\hline Sheat gas flow & 80 a.u. & 80 a.u. & 80 a.u. & 80 a.u. \\
\hline Auxiliary gas flow & 20 a.u. & 20 a.u. & 0 a.u. & 0 a.u. \\
\hline Tube lens offset & $+20 \mathrm{~V}$ & $0 \mathrm{~V}$ & $+20 \mathrm{~V}$ & $-50 \mathrm{~V}$ \\
\hline First octapole voltage & $-1.50 \mathrm{~V}$ & $+2.75 \mathrm{~V}$ & $-3.50 \mathrm{~V}$ & $+3.00 \mathrm{~V}$ \\
\hline Interoctapole voltage & $-16.0 \mathrm{~V}$ & $+24.0 \mathrm{~V}$ & $-16.0 \mathrm{~V}$ & $+16.0 \mathrm{~V}$ \\
\hline Second octapole voltage & $-5.50 \mathrm{~V}$ & $+7.00 \mathrm{~V}$ & $-6.00 \mathrm{~V}$ & $+7.00 \mathrm{~V}$ \\
\hline Tuning method for the signal at & $m / z 155$ & $m / z 394$ & $\mathrm{~m} / \mathrm{z} 155$ & $\mathrm{~m} / \mathrm{z} 182$ \\
\hline
\end{tabular}

\section{Hydrolytic Degradation Conditions}

Ten $\mathrm{mL}$ of a $5.00 \mathrm{mg} \mathrm{L}^{-1}$ solution of tribenuron methyl in ultrapure water are introduced in a quartz cell protected by aluminium foil and put at dark at temperature of $21 \pm 1^{\circ} \mathrm{C}$. At prefixed times $(4,9,16,24,30$, and $40 \mathrm{~h}$ ) aliquots were collected and underwent HPLCDAD analysis.

\section{Solar Box Irradiation Conditions}

Ten $\mathrm{mL}$ of $5.00 \mathrm{mg} \mathrm{L}^{-1}$ solution of the herbicide, in ultrapure water and in paddy waters (collected in a wet rice field near Casale Monferrato, Alessandria, Italy) respectively, were introduced in quartz cells and exposed to solar box irradiation for established exposure times. The instrumental conditions were chosen on the basis of sun average irradiation and temperature in the period May to September, as monitored by the meteorological station of the DISTA Department of our University. Radiation density of the xenon lamp was set at $260 \mathrm{~W} \mathrm{~m}^{-2}$ and temperature at $30^{\circ} \mathrm{C}$. The filter for light radiation employed was an outdoor UV filter. The conditions were checked through comparative experiments performed on solutions irradiated both with sun light and solar box. Since the degradation results are the same, solar box irradiation is used in all the following experiments, because it ensures natural sun light, continuous availability, and constant intensity.

\section{UV Lamp Irradiation Conditions}

Ten $\mathrm{mL}$ of a $5.00 \mathrm{mg} \mathrm{L}^{-1}$ solution of the herbicide in ultrapure water, contained in quartz cells, are exposed for times ranging between 0 and $20 \mathrm{~min}$ to the UV lamp irradiating at $254 \mathrm{~nm}$.

\section{Chemical Oxygen Demand Conditions}

The method consists in the determination of the amount $\left(\mathrm{mg} \mathrm{L}^{-1}\right)$ of dissolved oxygen required for the oxidation of all the species present in a water sample under strong conditions as those induced by the addition of potassium dichromate in acidic environment and high temperature. According to the normative ISO6060:1989 [30], $10.0 \mathrm{~mL}$ of $5.00 \mathrm{mg} \mathrm{L}^{-1}$ tribenuron methyl water solution are added of $15.0 \mathrm{~mL}$ of $\mathrm{H}_{2} \mathrm{SO}_{4} 96 \%$ and of $5.0 \mathrm{~mL}$ of $0.25 \mathrm{~N} \mathrm{~K}_{2} \mathrm{Cr}_{2} \mathrm{O}_{7}$. The solution was boiled for $2 \mathrm{~h}$, cooled, and the dichromate excess titrated with $0.025 \mathrm{~N}$ $\mathrm{Fe}(\mathrm{II})$ solution, ferroin as the indicator. The chemical oxygen demand (COD) (given in $\mathrm{mg} \mathrm{L}^{-1}$ of dissolved oxygen) was calculated as:

$$
C O D=\frac{\left(v_{0}-v_{x}\right) \cdot N \cdot 8000}{v}
$$

where $v_{0}$ and $v_{x}$ are the volumes $(\mathrm{mL})$ of $\mathrm{Fe}(\mathrm{II})$ solution at normality $N$, respectively, used in the titration of the blank and of the sample; $v$ is the volume $(\mathrm{mL})$ of the sample solution.

The analysis was performed for the herbicide solutions that were (1) preserved in the dark, (2) underwent solar box irradiation, and (3) underwent UV lamp irradiation.

\section{Ecotoxicological Biotests}

The tests are based on the effects induced by potentially toxic species on organisms characterized by suitable properties. The toxic effect depends on the pollutant concentration and is due to the interaction between the pollutant and the bioindicator or specific parts of its organism, when they are put in contact for prefixed times. In this paper, the biotests more frequently used are applied, in particular those based on Daphnia magna (acute test), Pseudokirchneriella subcapitata (subchronic test) and Vibrio fischeri (acute test).

Daphnia magna is a freshwater crustacean; the toxicity response was given by its immobilization and requires $24 \mathrm{~h}$ of exposure [31]. Pseudokirchneriella subcapitata is a unicellular freshwater alga; the test was based on the inhibition of the algal growing, evaluated through a direct electronic counting of the cellules. The results 
were obtained after $72 \mathrm{~h}$ of exposure [32]. The third test was based on the effects produced on Vibrio fischeri, which is a bioluminescent gram-negative bacter living in sea waters. The effects consist in a natural decrease of bioluminescence due to the inhibition of luciferase and the results are obtained after 15 min of exposure: this test ensures repeatability, accuracy, and sensitivity [33]. The results of all the tests are expressed as $\mathrm{I} \%$, which indicates the percentage of inhibition induced by the chemical on the activity of the organisms after a prefixed time of exposure. Higher values of $\mathrm{I} \%$ correspond to higher toxicity. In particular, when $\mathrm{I} \%$ ranges between $0 \%$ and $20 \%$, the sample is considered not toxic, weakly toxic for values between $20 \%$ and $50 \%$, and toxic for values greater than $50 \%$. When I\% greater than $50 \%$ are obtained, the value of EC50 must also be evaluated, which is the concentration of the chemical that induces an inhibitory effect of the order of $50 \%$.

\section{Results and Discussion}

\section{Degradation Studies Based on HPLC-DAD Analysis}

The herbicide solutions in ultrapure water, both those preserved in the dark and those that underwent solar box irradiation for times of 4, 9, 16, 24, 30, and $40 \mathrm{~h}$, were analyzed by HPLC-DAD.

As shown in Figure 1, the peak area of tribenuron methyl decreases along time, while three new peaks form and progressively increase. Their intensities are much lower for the dark control solution where the decrease of the herbicide signal is also lower.

To evaluate the degradation kinetics of both hydrolytic and photoinduced processes, from the chromatographic peak areas recorded at the different degradation times, the concentrations $C$ of the herbicide were evaluated through a calibration plot built in the concentration range $25.0-5000.0 \mu \mathrm{g} \mathrm{L^{-1 }}$. The values of $\ln C$ plotted as a function of time show in both cases a linear behavior and suggest that the degradation process always follows a first-order reaction.

The calculated $t_{1 / 2}$ values are around $170 \mathrm{~h}$ (kinetic constant $0.004 \mathrm{~h}^{-1}$ ) and $6.80 \mathrm{~h}$ (kinetic constant 0.102 $\mathrm{h}^{-1}$ ) for hydrolysis and photoinduced degradation reactions, respectively.

\section{Determination of Chemical Oxygen Demand $(C O D)$}

The evaluation of COD performed for tribenuron methyl solution $\left(5.00 \mathrm{mg} \mathrm{L}^{-1}\right.$ ) photoirradiated in solar box at different times ranging from $0 \mathrm{~min}$ to $40 \mathrm{~h}$ (time greater than the life time) indicates that the COD value progressively decreases and that, after $40 \mathrm{~h}$ of irradiation, a complete mineralization is not achieved but about $28 \%$ of the initial amount of oxidizable species is still present. The same analysis performed for the solution preserved in the dark for the same time (40 h) indicates a residual amount of oxidizable species around $75 \%$.

\section{Mass Characterization of Tribenuron Methyl}

To investigate the structures of the degradation products, HPLC-MS/MS analysis was employed. A mass spectrometry characterization of tribenuron methyl was previously carried out to optimize the conditions of the instrumental sensitivity of mass spectrometry analysis and to build a fragmentation pattern that could be useful in the identification of the photodegradation products. The characterization was performed through a direct infusion of $10.00 \mathrm{mg} \mathrm{L^{-1 }}$ tribenuron methyl water solution and the pattern obtained is summarized in Table 2. The PI ESI analysis shows three signals at $\mathrm{m} / \mathrm{z}$ 418,396 , and 155. The MS/MS fragmentation of $m / z 418$

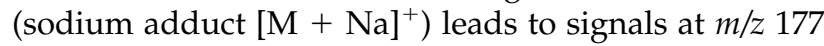
and 264. Due to the cleavage of the $\mathrm{C}-\mathrm{N}$ bond, two structures form: the signal at $\mathrm{m} / \mathrm{z} 177$ corresponds to the adduct between sodium atom and 2-methoxy-4methylamino-6-methyl-1,3,5-triazine (afterwards called P1) while the fragment at $m / z 264$ corresponds to the complementary piece of the molecule $[\mathrm{M}-\mathrm{P} 1+\mathrm{Na}]^{+}$. The MS/MS fragmentation of the ion fragment at $\mathrm{m} / \mathrm{z}$ 155 gives fragments at $m / z 114,98,96,85,83,57$, and 56 (structures deriving from the opening of the triazinic ring) and allows to ascribe to the signal at $m / z 155$ the structure of 2-methoxy-4-methylamino-6-methyl-1,3,5triazine $[\mathrm{P} 1+\mathrm{H}]^{+}$.

The MS/MS fragmentation of the ion at $m / z 396$ $\left([\mathrm{M}+\mathrm{H}]^{+}\right)$gives signals at $m / z 155$ (already mentioned) and $m / z$ 364, which correspond to the species [M $\left.\mathrm{OCH}_{3}\right]^{+}$as confirmed by the successive fragmentation into the ions at $m / z 181,138,123$, and 82 .

The analyte also ionizes in NI ESI, giving a signal at $m / z$ 394, which corresponds to the $[\mathrm{M}-\mathrm{H}]^{-}$structure; the MS/MS fragmentation gives signals at $m / z 153$ $[\mathrm{P} 1-\mathrm{H}]^{-}$(confirmed by the successive fragmentation in the ions at $m / z 139,123$, and 55) and $m / z 182$, together with $\mathrm{MS}^{3}$ ions at $m / z 138,118$, and 62 .

Mass spectrometry characterization is confirmed by both PI and NI APCI. PI APCI analysis identifies the signal at $m / z$ 155, which gives the same fragments already obtained in PI ESI. In NI APCI, the precursor ion gives a signal at $m / z 394[\mathrm{M}-\mathrm{H}]^{-}$, whose MS/MS fragmentation gives signals at $m / z 153$ (already found in NI ESI) and at $m / z$ 182, which in turn gives a fragment at $m / z 106$ to which the structure of sulfonyl isocyanate is ascribed.

\section{HPLC-MS/MS Analysis of Tribenuron Methyl Aqueous Solutions Undergone to Photoirradiation and Preserved in the Dark}

The samples collected after 4, 9, 16, 24, 30, and $40 \mathrm{~h}$ of solar box irradiation underwent to HPLC-MS/MS analysis. The HPLC-PI ESI MS/MS chromatogram of tribe- 


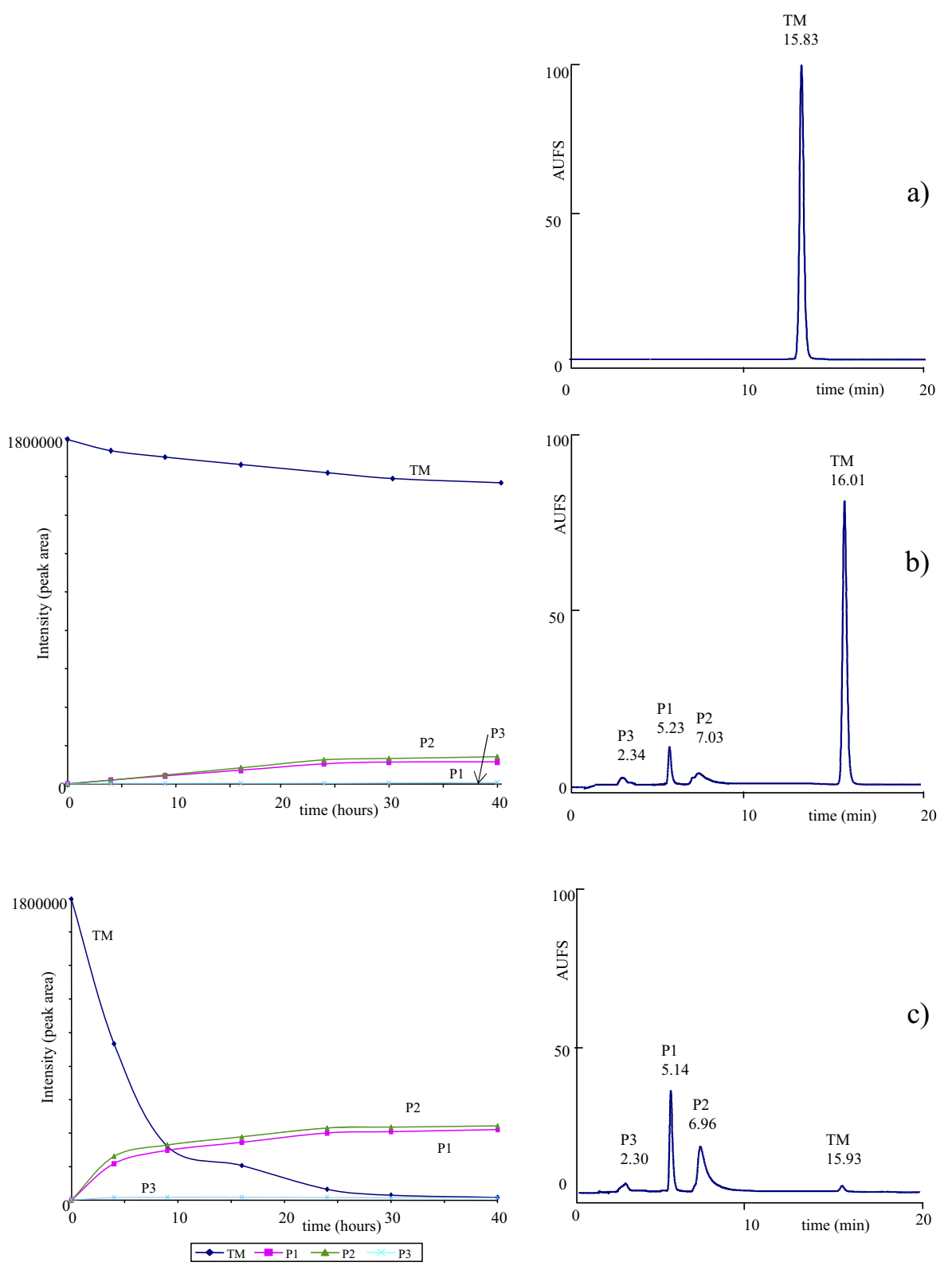

Figure 1. HPLC-DAD chromatograms of tribenuron methyl (TM) aqueous solution $\left(5.00 \mathrm{mg} \mathrm{L}^{-1}\right)$ and its degradation products P1, P2 and P3: (a) time = 0; (b) after $40 \mathrm{~h}$ at dark; (c) after $40 \mathrm{~h}$ under solar box irradiation. The stationary phase is a Lichrospher column RP-18 endcapped ( $5 \mu \mathrm{m}, 250 \mathrm{~mm} \times$ $4 \mathrm{~mm}$ i.d.) with a $15 \mathrm{~mm} \times 4 \mathrm{~mm}$ Lichrospher RP-18 $(5 \mu \mathrm{m})$ guard precolumn. The mobile phase is a mixture $55 / 45 \% \mathrm{vol} / \mathrm{vol}$ of acetonitrile and acidified water $(0.05 \% \mathrm{vol} / \mathrm{vol}$ for acetic acid), flowing at $0.5 \mathrm{~mL} \mathrm{~min}{ }^{-1}$. Injection volume is $20.0 \mu \mathrm{L}$. The respective peak area variations as a function of time are also reported at the left of $(\mathbf{b})$ and $(\mathbf{c})$.

nuron methyl aqueous solutions, recorded after $4 \mathrm{~h}$ of irradiation, shows, together with the peak of tribenuron methyl $\left(t_{R}\right.$ about $\left.16 \mathrm{~min}\right)$, the presence of a peak at retention time of about 5.6 min with $\mathrm{m} / \mathrm{z} 155$, which progressively increases with the degradation time. The signal already evidenced in MS/MS characterization is assigned to $[\mathrm{P} 1+\mathrm{H}]^{+}$. According to the seven fragments obtained in PI ESI and PI APCI MS/MS analyses $(\mathrm{m} / \mathrm{z} 114,98,96,85,83,57$, and 56) and to the three fragments obtained in NI ESI and NI APCI MS/MS analyses $(m / z 139,123$, and 55), the molecular structure for the degradation product of $154 \mathrm{Da}$ (P1) is proposed (Figure 2).

HPLC-NI ESI MS/MS chromatogram shows the presence of two byproducts at $\mathrm{m} / z 214[\mathrm{P} 2-\mathrm{H}]^{-}$and $\mathrm{m} / \mathrm{z} 182[\mathrm{P} 3-\mathrm{H}]^{-}$(Figure 3). By further fragmentation of $[\mathrm{P} 2-\mathrm{H}]^{-}$, the signal of $[\mathrm{P} 3-\mathrm{H}]^{-}$at $\mathrm{m} / z 182$ is evidenced. The corresponding species $\mathrm{P} 3$ likely forms through cleavage of a $\mathrm{C}-\mathrm{N}$ bond, loss of a $\mathrm{CH}_{3} \mathrm{OH}$ unit, and cyclization of the molecule through the formation of a "bridge" bond between the nitrogen atom bound to $-\mathrm{SO}_{2}$ group and the carbon atom of the carbonylic 
Table 2. Mass spectrometry ESI and APCI characterization of tribenuron methyl in both PI and NI mode

\begin{tabular}{|c|c|c|c|c|c|c|}
\hline & \multicolumn{3}{|c|}{ Positive ion mode } & \multicolumn{3}{|c|}{ Negative ion mode } \\
\hline & Precursor ion $(\mathrm{m} / \mathrm{z})$ & $\begin{array}{c}\text { Product ion } \\
\left(\mathrm{m} / \mathrm{z} \mathrm{MS}^{2}\right)\end{array}$ & $\begin{array}{c}\text { Product ion } \\
\left(m / z \mathrm{MS}^{3}\right)\end{array}$ & Precursor ion $(\mathrm{m} / \mathrm{z})$ & $\begin{array}{c}\text { Product ion } \\
\left(\mathrm{m} / \mathrm{z} \mathrm{MS}^{2}\right)\end{array}$ & $\begin{array}{c}\text { Product ion } \\
\left(\mathrm{m} / \mathrm{z} \mathrm{MS}^{3}\right)\end{array}$ \\
\hline \multirow[t]{15}{*}{ ESI } & & 177 & & & & 139 \\
\hline & 418 & & & & 153 & 123 \\
\hline & & 264 & & & & 55 \\
\hline & 396 & 155 & & 394 & 182 & 138 \\
\hline & & 364 & 181 & & & 118 \\
\hline & & & 138 & & & 62 \\
\hline & & & 123 & & & \\
\hline & & & 82 & & & \\
\hline & 155 & 114 & & & & \\
\hline & & 98 & & & & \\
\hline & & 96 & & & & \\
\hline & & 85 & & & & \\
\hline & & 83 & & & & \\
\hline & & 57 & & & & \\
\hline & & 56 & & & & \\
\hline \multirow[t]{7}{*}{$\mathrm{APCl}$} & 155 & 114 & & 394 & 153 & 139 \\
\hline & & 98 & & & & 123 \\
\hline & & 96 & & & & 55 \\
\hline & & 85 & & & 182 & 106 \\
\hline & & 83 & & & & \\
\hline & & 57 & & & & \\
\hline & & 56 & & & & \\
\hline
\end{tabular}

group in the aromatic ring. The MS/MS analysis of the fragment at $m / z 182$, both in full scan spectrum or generated by the fragmentation of the ion at $m / z 214$, gives a product ion at $m / z$ 106. HPLC-NI APCI MS/MS analysis confirms the presence of the signal at $m / z 182$, which gives the same fragmentation obtained in NI ESI.

The same analyses, performed for the solutions of tribenuron methyl preserved in the dark for $40 \mathrm{~h}$, indicate the presence of the same degradation products, whose intensity is, however, much lower.

On the basis of the ESI and APCI MS/MS results, the whole degradation pathway of tribenuron methyl is proposed in Figure 2.

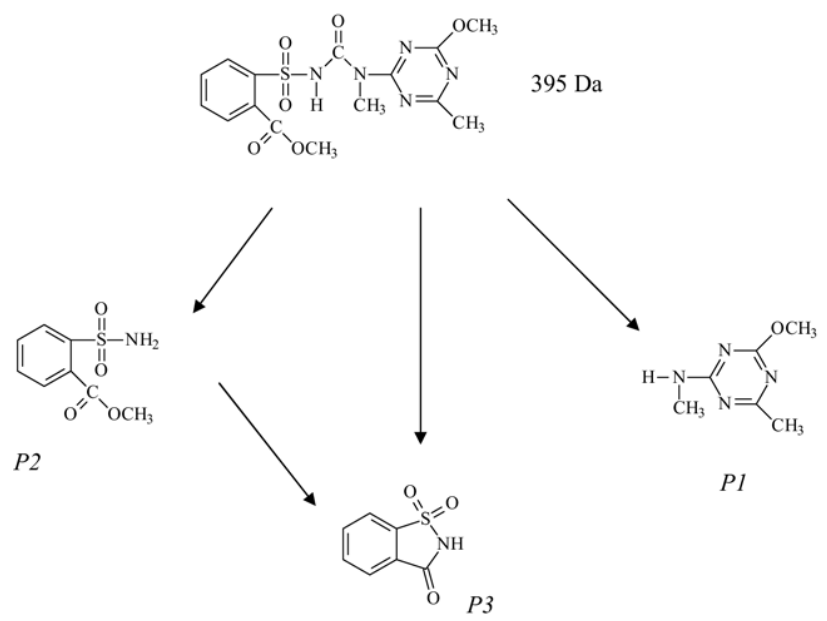

Figure 2. Degradation pathway of tribenuron methyl for hydrolysis and solar box irradiations.
Since for the chemicals identified as P1, P2, and P3 reference standards are available, a determination is performed for both hydrolytic and photoirradiated degradation products by building calibration plots of peak areas as a function of concentration ranging between 30 and $5000 \mu \mathrm{g} \mathrm{L}^{-1}$. $\mathrm{R}^{2}$ values consistently greater than 0.9989 are obtained. The quantitation data are reported in Table 3. The results indicate that hydrolysis reactions account for about $12 \%$ with respect to the degradation extent observed for photoirradiation, as roughly indicated also from COD evaluation. As concerns the degradation products, it can be observed that $\mathrm{P} 1$ and $\mathrm{P} 2$ form at greater amounts with respect to P3; the result is likely due to the preferential pathway that for cleavage of the $\mathrm{C}-\mathrm{N}$ bond leads to the simultaneous formation of $\mathrm{P} 1$ and $\mathrm{P} 2$.

\section{HPLC-DAD-MS/MS Analysis of Tribenuron Methyl Solutions in Paddy Water that Underwent Solar Box Irradiation}

To check a possible matrix effect, the study was also performed for solution $5.00 \mathrm{mg} \mathrm{L}^{-1}$ of tribenuron methyl in paddy water that underwent solar box irradiation for times 5, 13, 15, 18, and 20 days. Also, in paddy water solution the degradation process is firstorder reaction with a value of $t_{1 / 2}$ of $120 \mathrm{~h}$ (kinetic constant $=0.006 \mathrm{~h}^{-1}$ ), much greater than that obtained in ultrapure water solution $\left(t_{1 / 2}=6.80 \mathrm{~h}\right)$ that underwent irradiation but lower with respect to dark control. The different values obtained in ultrapure water solution ( $\mathrm{pH}$ around 5.7) and paddy waters ( $\mathrm{pH}$ around 8.3) 


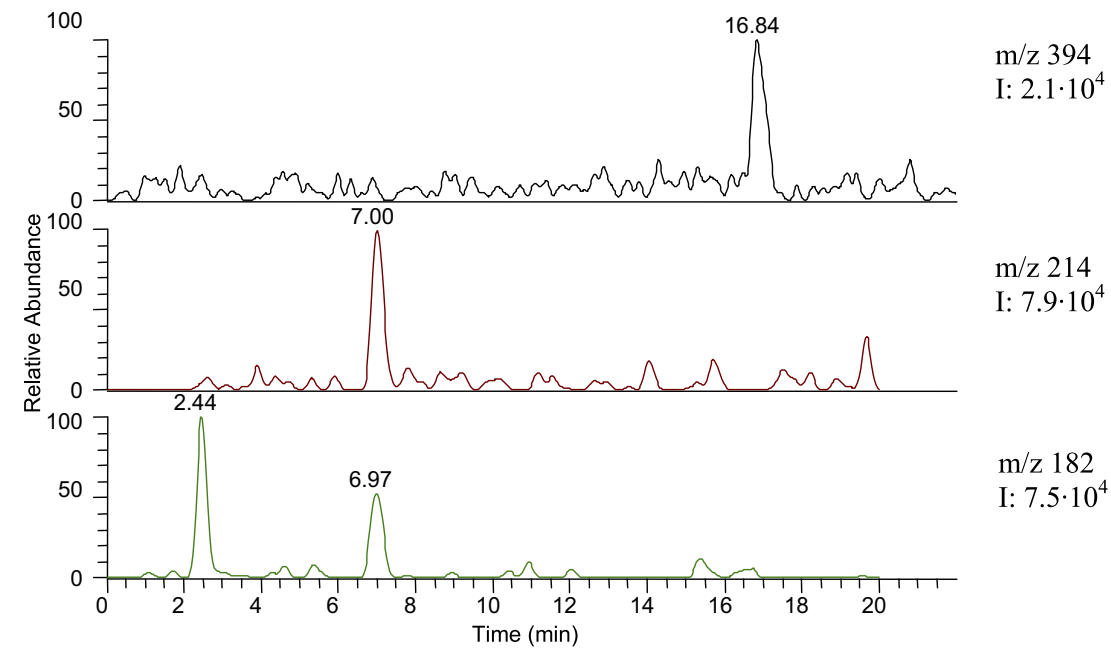

Figure 3. Typical HPLC-NI ESI MS/MS chromatogram of $5.00 \mathrm{mg} \mathrm{L}^{-1}$ tribenuron methyl aqueous solution after $40 \mathrm{~h}$ of solar box irradiation. Chromatographic conditions as in Figure 1 . The eluate flow from HPLC is split 1:1 before the introduction in the ESI source.

could be due to a matrix effect of the natural waters as well as to the different $\mathrm{pH}$ value, in agreement with literature results obtained for two other sulfonylurea herbicides, which show that photodegradation is faster for lower $\mathrm{pH}$ values [34]. Taking into account the $\mathrm{pKa}$ value for tribenuron methyl $\left(5.00 \mathrm{~mol} \mathrm{~L}^{-1}\right.$ [35], the percentage of the undissociated form of tribenuron methyl is around $17 \%$ in ultrapure water and only $0.5 \%$ in paddy water.

The solutions analyzed in HPLC-DAD-MS/MS, both in ESI and APCI sources, evidence the formation of the same products identified when the solvent is ultrapure water. Apart from the different half life time, the degradation pathway in paddy waters follows the same patterns (hydrolytic and photoinduced) found in ultrapure water.

Figure 4 reports typical HPLC-PI APCI MS/MS chromatograms, recorded at different irradiation times; in paddy water, the peak of tribenuron methyl $\left(t_{R}\right.$ about $16 \mathrm{~min})$ decreases with time and after 13 days of irradiation the degradation product $\mathrm{P} 1 \quad\left(\mathrm{t}_{\mathrm{R}}\right.$ about 5.6 $\min , m / z$ 155) forms.

\section{Degradation Pathway of Tribenuron Methyl Ultrapure Water Solution When Irradiated with UV Lamp}

To verify how the wavelength of irradiation source can affect the degradation pathway, a set of experiments is performed irradiating with UV lamp (254 nm) $5.00 \mathrm{mg}$ $\mathrm{L}^{-1}$ ultrapure water solutions of tribenuron methyl, for times of $1,3,6,12$, and $20 \mathrm{~min}$. The degradation kinetics evaluated by the HPLC-DAD data ars first-order (as with solar box irradiation), but half life time $\left(\mathrm{t}_{1 / 2}=0.88\right.$ $\min , \mathrm{k}=0.79 \mathrm{~min}^{-1}$ ) is much lower.

COD evaluation on the solution exposed to UV irradiation for $20 \mathrm{~min}$ indicates that also in this photodegradation process a complete mineralization is not achieved but around $24 \%$ of oxidizable organic species are still present.

The HPLC-ESI MS/MS total ion chromatogram in PI mode, both in ESI and APCI source, shows the presence, confirmed by the fragmentation pattern, of the product P1 $(m / z$ 155) already identified in solar box irradiation.

Analogously, the chromatogram recorded in NI mode shows the presence of a peak corresponding to $m / z 215$ identified as $[\mathrm{P} 4-\mathrm{H}]^{-}$(whose area increases with the degradation time) not present in the solutions that underwent solar box irradiation. MS/MS analysis evidences a signal at $\mathrm{m} / \mathrm{z} 151$ (loss of a $-\mathrm{SO}_{2}$ group) and for further fragmentation, two fragments at $\mathrm{m} / \mathrm{z} 121$ and $m / z 107$, likely due to the loss of a methoxy and a $\mathrm{CO}_{2}$ groups, respectively.

HPLC-MS/MS both in NI ESI and NI APCI modes evidence an ion at $m / z 182$, which for further fragmentation gives ions at $\mathrm{m} / \mathrm{z} 118$ and 138. It is worth noting that a signal at $m / z 182$ has been also evidenced in the

Table 3. Quantitation of tribenuron methyl and of degradation products

\begin{tabular}{lcccc}
\hline & Tribenuron methyl $\left(\mathrm{mg} \mathrm{L}^{-1}\right)$ & $\mathrm{P} 1\left(\mathrm{mg} \mathrm{L}^{-1}\right)$ & $\mathrm{P} 2\left(\mathrm{mg} \mathrm{L}^{-1}\right)$ & $\mathrm{P} 3\left(\mathrm{mg} \mathrm{L}^{-1}\right)$ \\
\hline \hline $\mathrm{t}=0$ & $5.00 \pm 0.01$ & n.d. & n.d. & n.d. \\
Dark $\mathrm{t}=40 \mathrm{~h}$ & $4.40 \pm 0.01$ & $0.23 \pm 0.01$ & $0.28 \pm 0.01$ & $0.03 \pm 0.01$ \\
Solar box $\mathrm{t}=40 \mathrm{~h}$ & n.d. & $2.40 \pm 0.10$ & $1.90 \pm 0.01$ & $0.70 \pm 0.03$ \\
\hline
\end{tabular}

a n.d. $<$ LOD. 


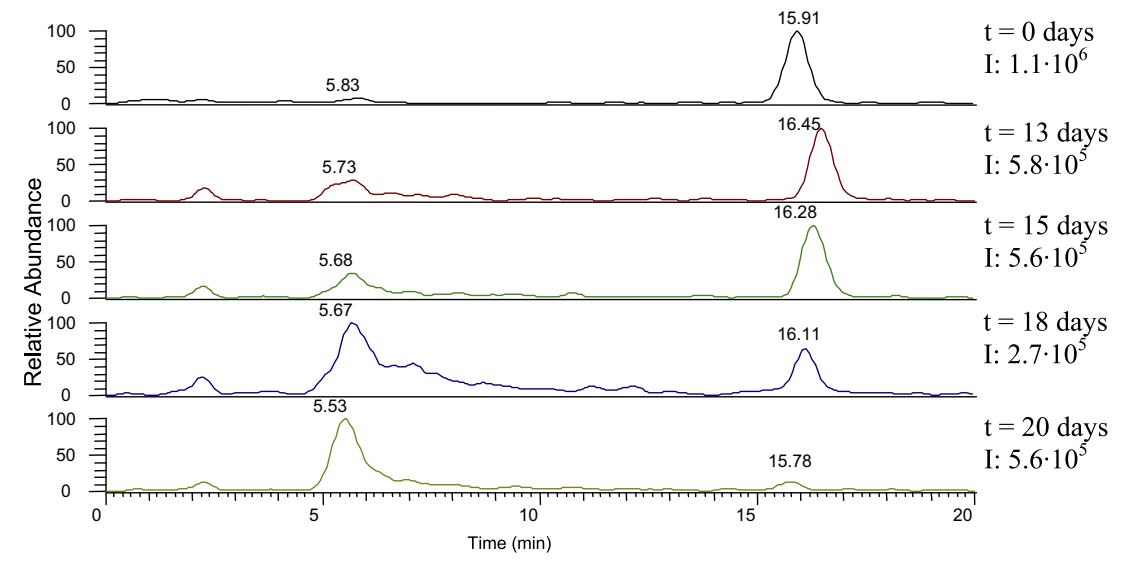

Figure 4. HPLC-PI APCI MS/MS chromatograms extracted at $\mathrm{m} / \mathrm{z} 155$ of tribenuron methyl solutions in paddy water at typical times of solar box irradiation. Chromatographic conditions as in Figure 1.

degradation pathway induced by solar box irradiation (P3), but the different fragmentation pattern shows that, notwithstanding the same $\mathrm{m} / \mathrm{z}$ ratio the structures of the two species are different. Figure 5 shows, for comparison, the pathways obtained for hydrolysis, solar box, and UV irradiation; only the product P1 is common to the three pathways.

\section{Ecotoxicological Tests}

The tests have been performed on solutions of tribenuron methyl in ultrapure water at concentration corresponding to the threshold level: $0.1 \mu \mathrm{g} \mathrm{L}^{-1}$, both not irradiated and solar box irradiated [36]. Each experiment is repeated three times. The results of the Vibrio fischeri test indicate no toxicity, with I\% values lower than $20 \%$. On the contrary, the Daphnia magna and Pseudokirchneriella subcapitata tests give indication of toxicity, with average I\% values around $80 \%$ for both the solutions, before and after the photoirradiation process. For the same solutions, the values of EC50 indicate negligible toxicity levels, in agreement with the results of Vibrio fischeri test. All the results together

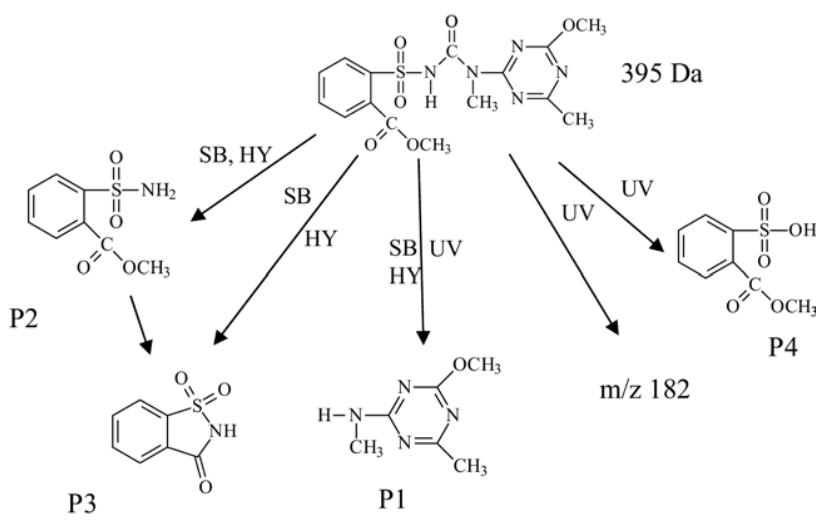

Figure 5. Comparison of the degradation pathways for hydrolysis dark control (HY), solar box (SB), and UV lamp (UV) irradiations. seem to suggest a response of border line toxicity, which can be correlated with the concentration chosen for the experiments, i.e., the threshold concentration allowed in surface waters. In any case, the toxicity level found for the degradation products is not lower than that of the herbicide itself.

\section{Conclusions}

The results obtained show that tribenuron methyl in aqueous solutions preserved in the dark undergo degradation that accounts for about $12 \%$ with respect to that observed for photoirradiation simulating sun light, which is likely due to both phenomena. Even if the kinetics are much slower for hydrolysis, HPLC-DADMS/MS analyses indicate that the products formed are the same. The same products also form for irradiation in the presence of paddy waters with kinetics that are faster than that of pure hydrolysis and slower with respect to photoirradiation in ultrapure water.

The three degradation products identified in this photodegradation study correspond to some of the products evidenced by other authors who also propose other fragments $[6,8,11,23,25,37]$. This stronger fragmentation found in literature could be due to the different pretreatment of the solutions that underwent photoirradiation before the injection in the chromatographic system as well as to the gas chromatographic conditions used or to the use of organic solvents [23-25].

\section{Acknowledgments}

The authors gratefully acknowledge financial support by ATF (Associazione Ambiente-Territorio e Formazione, Alessandria Italy), by Regione Piemonte, Direzione Igiene e Sanità Pubblica (Turin, Italy), and by MIUR (Ministero Italiano Università e Ricerca, Rome, Italy). They thank Professor E. Ferrero (University of Piemonte Orientale, DISTA Department) for the data of the meteorological station. 


\section{References}

1. Andersen, S. M.; Hertz, P. B.; Holst, T.; Bossi, R.; Jacobsen, C. S. Mineralization Studies of ${ }^{14} \mathrm{C}$-Labeled Metsulfuron-Methyl, Tribenuron-Methyl, Chlorsulfuron, and Thifensulfuron-Methyl in One Danish Soil and Groundwater Sediment Profile. Chemosphere 2001, 45, 775-782.

2. Martins, J. M. F.; Mermoud, A. Transport of Rimsulfuron and Its Metabolite in Soil Columns. Chemosphere 1999, 38, 601-616.

3. Metzger, L. O. Y.; Munier-Lamy, C.; Choné, T.; Belgy, M.-J.; Andreux, F.; Védy, J.-C. Fate of a Sulfonylurea Herbicide in an Alluvional Soil, as Shown by Experimental Degradation of Pyrimidine- $2{ }^{14} \mathrm{C}$-labeled rimsulfuron. Chemosphere 1996, 33, 625-633.

4. Livanainen, E.; Heinonen-Tanski, H. Degradation and Leaching of Chlorsulfuron in Three Different Soils. Acta. Agric. Scand. 1991, 41, 85-92.

5. Martins, J. M. F.; Chevre, N.; Spack, L.; Tarradellas, J.; Mermoud, A. Degradation in Soil and Water and Ecotoxicity of Rimsulfuron and Its Metabolites. Chemosphere 2001, 45, 515-522.

6. Olmedo, C.; Deban, L.; Coca, M.; Vega, M.; de la Rosa, F. Electrochemical Study of the Herbicide Tribenuron. Fresenius J. Anal. Chem. 1997, 31, 253-260.

7. Sarmah, A. K.; Sabadie, J. Hydrolysis of Sulfonylurea Herbicides in Soils and Aqueous Solutions: A Review. J. Agric. Food Chem. 2002, 50, 6253-6265.

8. Perreau, F.; Bados, P.; Kerhoas, L.; Nélieu, S.; Einhorn, J. Trace Analysis of Sulfonylurea Herbicides and Their Metabolites in Water Using a Combination of Off-Line or On-Line Solid-Phase Extraction and Liquid Chromatography-Tandem Mass Spectrometry. Anal. Bioanal. Chem. 2007, 388, 1265-1273.

9. Wei, L.; Yu, H.; Sun, Y.; Fen, J.; Wang, L. The Effects of Three Sulfonylurea Herbicides and Their Degradation Products on the Green Algae Chlorella pyrenoidosa. Chemosphere 1998, 37, 747-751.

10. Saha, S.; Kulshrestha, G. Degradation of Sulfosulfuron, a Sulfonylurea Herbicide, as Influenced by Abiotic Factors. J. Agric. Food Chem. 2002, 50, 4572-4575.

11. Bossi, R.; Vejrup, K.; Jacobsen, C. S. Determination of Sulfonylurea Degradation Products in Soil by Liquid Chromatography-Ultraviolet Detection Followed by Confirmatory Liquid Chromatography-Tandem Mass Spectrometry. J. Chromatogr. A 1999, 855, 575-582.

12. Lee, J. K.; Führ, F.; Kwon, J. W.; Ahn, K. C. Long-Term Fate of the Herbicide Cinosulfuron in Lysimeters Planted with Rice Over Four Consecutive years. Chemosphere 2002, 49, 173-181.

13. Khan, M. N.; Bakar, B. B.; Yin, F. W. N. Kinetic Study on Acid-Base Catalyzed Hydrolysis of Azimsulfuron, a Sulfonylurea Herbicide. Int. J. Chem. Kinet. 1999, 31, 253-260.

14. Shalaby, L. M.; Bramble, F. O. Jr.; Lee, P. W. Application of Thermospray LC/MS for Residue Analysis of Sulfonylurea Herbicides and Their Degradation Products. J. Agric. Food Chem. 1992, 40, 513-517.

15. Berger, B. M.; Janowitz, K.; Menne, H. J.; Hoppe, H. H. Comparative Study of Microbial and Chemical Transformation of Eleven Sulfonylurea Herbicides in Soil. Z. Planzenkrankh. Pflanzenshutz (J. Plant Dis. Prot.) 1998, 105, 611-623.

16. Pusino, A.; Braschi, I.; Petretto, S.; Gessa, C. Photodegradation of Herbicide Triasulfuron. Pestic. Sci. 1999, 55, 479-481.
17. Vulliet, E.; Emmelin, C.; Chovelon, J.-M.; Guillard, C.; Herrmann, J.-M. Photocatalytic Degradation of Sulfonylurea Herbicides in Aqueous $\mathrm{TiO}_{2}$. Appl. Catal. B 2002, 38, 127-137.

18. Vulliet, E.; Chovelon, J.-M.; Guillard, C.; Hermann, J.-M. Factors Influencing the Photocatalytic Degradation of Sulfonylurea Herbicides by $\mathrm{TiO}_{2}$ Aqueous Suspension. J. Photochem. Photobiol. 2003, 159, 71-79.

19. Maurino, V.; Minero, C.; Pelizzetti, E.; Vincenti, M. Photocatalytic Transformation of Sulfonylurea Herbicides Over Irradiated Titanium Dioxide Particles. Colloids Surf. A 1999, 151, 329-338.

20. Sleiman, M.; Ferronato, C.; Fenet, B.; Baudot, R.; Jaber, F.; Chovelon, J.-M. Development of HPLC/ESI-MS and HPLC $/{ }^{1} \mathrm{H}$ NMR Methods for the Identification of Photocatalytic Degradation Products of Iodosulfuron. Anal. Chem. 2006, 78, 2957-2966.

21. Pinna, M. V.; Zema, M.; Gessa, C.; Pusino, A. Structural Elucidation of Phototransformation Products of Azimsulfuron in Water. J. Agric. Food Chem. 2007, 55, 6659-6663.

22. European Commission Directive $94 / 37 /$ EC of 22 July1994 concerning the placing of pesticides on the market.

23. Bhattacharjee, A. K.; Dureja, P. Light-Induced Transformation of Tribenuron-Methyl on Glass, Soil, and Plant Surface. J. Environ. Sci. Health B 2002, 37, 131-140.

24. Bhattacharjee, A. K.; Dureja, P. Light Induced Transformation of TribenuronMethyl. Chemosphere 1999, 38, 741-749.

25. Bhattacherjee, A. K.; Dureja, P. Light Induced Transformations of Tribenuron Methyl in Aqueous Solutions. Pestic. Sci. 1999, 55, 183-188.

26. Caselli, M.; Light Induced Degradation of Metsulfuron-Methyl in Water. Chemosphere 2005, 59, 1137-1143.

27. Sabadie, J. Alcoholysis and Chemical Hydrolysis of BensulfuronMethyl. Weed Res. 1996, 36, 441-448.

28. Sabadie, J. Alcoolyse et hydrolyze chimique acide du chlorsulfuron Weed Res. 1991, 31, 309-316.

29. Polati, S.; Bottaro, M.; Frascarolo, P.; Gosetti, F.; Gianotti, V.; Gennaro, M. C. HPLC-UV and HPLC-MS ${ }^{n}$ Multiresidue Determination of Amidosulfuron, Azimsulfuron, Nicosulfuron, Rimsulfuron, Thifensulfuron Methyl, Tribenuron Methyl, and Azoxystrobin in Surface Waters. Anal. Chim. Acta 2006, 579, 146-151.

30. Normative ISO 6060:1989 Water Quality Determination of Chemical Oxygen Demand, 1989.

31. European Normative EN ISO 6341:1999 Water quality Determination of the inhibition of the mobility of Daphnia magna Straus (Cladocera, Crustacea) Acute Toxicity Test, 1999.

32. European Normative EN ISO 8692:2005 Water Quality Freshwater Algal Growth Inhibition Test with Unicellular Green Algae, 2005.

33. European Normative EN ISO 11348:2001 Water Quality Determination of the Inhibitory Effect of Water Samples on the Light Emission of Vibrio fischeri (Luminescent Bacteria Test), 2001.

34. Vulliet, E.; Emmelin, C.; Chovelon, J.-M. Influence of $\mathrm{pH}$ and Irradiation Wavelength on Photochemical Degradation of Sulfonylureas. J. Photochem. Photobiol. 2004, 163, 69-75.

35. http://www.ars.usda.gov.

36. European Directive 2000/60/CE of the European Parliament and of the Council establishing a framework for the Community action in the field of water policy, 2000

37. Di Loreto, H. E.; Czarnowski, J.; Alfonso, M. S. Kinetics of Hydrolysis and Cyclization of Ethyl 2-(Aminosulfonyl)benzoate to saccharin. Chemosphere 2002, 49, 353-361. 